\title{
9. Effect of Glutamate Decarboxylase- and GABA Transaminase-Inhibitors on the GABA $(\gamma$-Aminobutyric Acid) Level in the Isolated Pancreatic Islets and the Hippocampal Slice of the Rat in vitro
}

\author{
By Yasuhiro OKadA and Hiroshi TaNiguchi*) \\ Department of Neurochemistry, Tokyo Metropolitan Institute for \\ Neurosciences, 2-6, Musashidai, Fuchu-shi, Tokyo 183 \\ (Communicated by Teizo OGAWA, M. J. A., Jan. 12, 1980)
}

GABA ( $\gamma$-aminobutyric acid) which is mainly formed from glutamate by glutamate decarboxylase (GAD, EC 4.1.1.15) and degraded by GABA transaminase (GABA-T, EC 2.6.1.19) occurs to a large extent in the central nervous system (CNS). ${ }^{1)}$ A high concentration of GABA and high GAD activity as in the CNS were found in nonneural tissue such as the rat pancreatic islets and human insulinoma. ${ }^{2)}$ The inhibitors against GAD and GABA-T change the GABA level in the CNS. A carbonyl-trapping agent, such as hydroxamine and aminooxyacetic acid (AOAA), increases the GABA concentration in the brain in vivo by inhibiting the activity of GABA-T, although it partly inhibits GAD. ${ }^{3)} \gamma$-vinyl-GABA (4-amino-hex-5-enoic acid) is reported to be a GABA-T inhibitor, and its intraperitoneal application raises the GABA level in the brain. ${ }^{4)}$ Methoxypyridoxine, an antivitamin $\mathrm{B}_{6}$ and a potent GAD inhibitor decreases the GABA concentration in the CNS, causing a severe convulsion. ${ }^{5), 6)}$ 3-mercaptopropionic acid inhibits the GAD activity and reduces the GABA concentration in the brain. ${ }^{7}$ However, the effect of these GAD and GABA-T inhibitors have not been studied in detail on the GABA level of nonneural tissue. The effect of AOAA on the GAD of non-neural tissues, such as the kidney and chick embryo, was tested and AOAA activated the GAD in the non-neural tissue whereas it inhibited the neural GAD. ${ }^{8}$ In our previous report, ${ }^{9)}$ GAD in the human insulinoma was inhibited by AOAA and had the same properties as that in the CNS.

In the present investigation, we have studied the effect of AOAA, $\gamma$-vinyl-GABA, 3-mercaptopropionic acid, and methoxypyridoxine on the GABA level in the isolated pancreatic islets and the hippocampal

*) Taniguchi, H. was on leave from the Second Department of Internal Medicine, School of Medicine, Kobe University, Kobe, Japan. 
slices of rat in vitro to test whether or not the effect of these agents on the non-neural tissue is similar to that of the CNS.

Methods. Albino Wister rats (200-300 g) were anesthetized with pentobarbitone sodium $(50 \mathrm{mg} / \mathrm{ml} / \mathrm{kg})$, and the abdominal cavity was opened. The pancreas was carefully excised after an injection of $10 \mathrm{ml}$ of Krebs-Ringer bicarbonate solution containing collagenase (25 mg/10 ml, Boehringer Mannheim) into the pancreas through the choledox duct. The pancreas was chopped and incubated at $37^{\circ} \mathrm{C}$ with mechanical stirring to isolate the islets from the exogenous exocrine gland. This isolation of the islets was performed according to a minor modification of the method of Lacy and Kostianovsky. ${ }^{10)}$ Other rats were decapitated, and the brain was removed from the skull. The hippocampus, with dentate gyrus, subiculum, and presubiculum, was isolated and cut transversely on the long axis with a razor blade under a stereomicroscope. The thickness of the hippocampal slice was about $400 \mu \mathrm{m}$. After preincubation of the isolated islets and the hippocampal slices for at least $20 \mathrm{~min}$ in the standard medium (concentration in $\mathrm{mM}: \mathrm{NaCl} 125, \mathrm{KCl} 5, \mathrm{KH}_{2} \mathrm{PO}_{4} 1.24, \mathrm{MgSO}_{4} 1.3, \mathrm{NaHCO}_{3} 26, \mathrm{CaCl}_{2}$ 1.3, glucose for pancreatic islets 3.3 and for hippocampal slice 10.0) which was stirred and kept under a $95 \% \mathrm{O}_{2}$ and $5 \% \mathrm{CO}_{2}$ atomosphere, the tissues were further incubated for $120 \mathrm{~min}$ in a standard medium containing AOAA, $\gamma$-vinyl-GABA, 3-mercaptopropionic acid or methoxypyridoxine. The concentration of each agent in the medium is described in Tables I and II. After incubation, the isolated islets were frozen on dry ice and freeze-dried in vacuo overnight $\left(-30^{\circ} \mathrm{C}\right)$. The freeze-dried samples were weighed with quarz fiber balance and used for the GABA assay. After incubation, the hippocampal slice was homogenized with 20 vol. of perchloric acid, and the homogenate was centrifuged (3000 rev/min, for $15 \mathrm{~min}$ ). The resulting supernatant was neutralized with $\mathrm{KHCO}_{3}$, and the supernatant was used for the GABA assay. The precipitate of the homogenate was dissolved with $0.5 \mathrm{~N} \mathrm{NaOH}$ and the protein of the tissue was determined by the method of Lowry et al. ${ }^{11}$ ) The detail of the GABA assay method was described elsewhere. ${ }^{12)}$ The GABA in the hippocampus and the isolated islets were measured by enzymatic and fluorometric methods. In the case of the GABA assay in the islets, the NADP-NADPH cycling system was introduced. AOAA was purchased from the Mann Research Lab. and methoxypyridoxine was obtained from Merck, Darmstadt. 3-mercaptopropionic acid was purchased from Daiichi Chemical Co., Tokyo. $\gamma$-vinyl-GABA was given with the courtesy of Centre de Recherche Merrell International, Strasbourg.

Results and discussion. Effect on the hippocampal slice. As shown in Table I, at the concentration between $1 \mu \mathrm{M}$ and $100 \mu \mathrm{M}$ of 
Table I. Effect of AOAA, $\gamma$-vinyl-GABA, methoxypyridoxine and 3-mercaptopropionic acid on the GABA level in the hippocampal slice in vitro

\begin{tabular}{lrrrr}
\hline & \multicolumn{4}{c}{ Concentration in the medium } \\
\cline { 2 - 5 } & $1 \mu \mathrm{M}$ & $10 \mu \mathrm{M}$ & $100 \mu \mathrm{M}$ & $1 \mathrm{mM}$ \\
\hline AOAA & $128.4 \pm 6.8$ & $121.6 \pm 7.6$ & $155.1 \pm 5.3$ & $61.7 \pm 5.6$ \\
\hline$\gamma$-vinyl GABA & $103.0 \pm 3.8$ & $158.3 \pm 10.1$ & $251.0 \pm 12.7$ & $128.5 \pm 8.9$ \\
\hline Methoxypyridoxine & $63.9 \pm 4.2$ & $62.3 \pm 3.3$ & $44.5 \pm 4.6$ & $86.3 \pm 3.0$ \\
\hline $\begin{array}{l}\text { 3-mercaptopropionic } \\
\text { acid }\end{array}$ & $88.5 \pm 9.1$ & $87.0 \pm 6.1$ & $64.6 \pm 4.7$ & $77.8 \pm 2.7$ \\
\hline
\end{tabular}

Values in the table indicate the percent \pm S.E.M. of the control concentration of GABA in the hippocampal slice, which was $28.8 \pm 2.1 \mathrm{mmol} / \mathrm{kg}$ protein $(\mathrm{N}=16)$. Each value was obtained from 4 to 5 hippocampal slices prepared from 5 rats.

these inhibitors in the medium, AOAA and $\gamma$-vinyl-GABA raised the GABA concentration in the slice, whereas methoxypyridoxine and 3-mercaptopropionic acid reduced it. The effect of AOAA on increasing the GABA level in the slice was not remarkable as reported in the in vivo experiment. ${ }^{13)}$ Only a $28 \%$ increase was observed at a concentration of $1 \mu \mathrm{M}$ of AOAA. It is important to note that the high concentration of AOAA $(1 \mathrm{mM})$ considerably reduced the GABA concentration in the slice probably because in high doses AOAA inhibited the GAD activity, as well as GABA-T. By increasing the concentration of $\gamma$-vinyl GABA, the GABA level in the tissue increased. A concentration of $100 \mu \mathrm{M}$ of $\gamma$-vinyl-GABA raised it to $251 \%$ of the original level, but at a concentration of $1 \mathrm{mM}$, the effect of raising the GABA concentration was not distinct. This may indicate again that high doses of $\gamma$-vinyl-GABA inhibited the GAD. Methoxypyridoxine, a GAD inhibitor, reduced the GABA level of the slice to $45 \%$ of the control sample at a concentration of $100 \mu \mathrm{M}$. However, at a concentration of $1 \mathrm{mM}$ methoxypyridoxine reduced the GABA level only by $14 \%$. In this case, high doses of methoxypyridoxine may also inhibit the GABA-T activity. 3-mercaptopropionic acid reduced the GABA level by increasing the dose of the agent. At a concentration of $1 \mathrm{mM}$ of 3-mercaptopropionic acid, the effect was again reversed, as observed in the other inhibitors. These results indicate that the effect of AOAA, $\gamma$-vinyl-GABA, 3-mercaptopropionic acid and methoxypyridoxine is complex in applications of high doses.

Effect on the isolated islets. To test the effect of these agents on the isolated islets, AOAA, $\gamma$-vinyl-GABA, methoxypyridoxine and 3 -mercaptopropionic acid were applied in the medium at the concentrations shown in Table II. The concentrations, $100 \mu \mathrm{M}$ and $1 \mathrm{mM}$ 
Table II. Effect of AOAA, $\gamma$-vinyl-GABA, methoxypyridoxine and 3mercaptopropionic acid on the isolated pancreatic islets in vitro

\begin{tabular}{rrrrc}
\hline $\begin{array}{r}\text { Concen- } \\
\text { tration }\end{array}$ & AOAA & $\gamma$-vinyl-GABA & $\begin{array}{c}\text { Methoxy- } \\
\text { pyridoxine }\end{array}$ & $\begin{array}{c}\text { 3-mercaptopro- } \\
\text { pionic acid }\end{array}$ \\
\hline $100 \mu \mathrm{M}$ & $\begin{array}{r}196.2 \pm 13.2 \\
(10 \mu \mathrm{M})\end{array}$ & $177.3 \pm 10.8$ & $83.7 \pm 6.2$ & $46.3 \pm 6.6$ \\
\hline $1 \mathrm{mM}$ & $110.2 \pm 5.3$ & $102.2 \pm 8.8$ & $92.5 \pm 9.2$ & $56.8 \pm 3.1$ \\
\hline
\end{tabular}

Values in the table indicate the percent \pm S.E.M. of the control value of GABA concentration in the isolated pancreatic islets. The control value was $11.3 \pm 0.9 \mathrm{mmol} / \mathrm{kg}$ by dry weight $(\mathrm{N}=55)$. Each value was obtained from 10 to 20 islets prepared from 3 animals.

were chosen because at the concentration of $100 \mu \mathrm{M}$, the most potent effect of these agents were obtained in the hippocampal slice, whereas the effect was reversed at the concentration of $1 \mathrm{mM}$. At low concentration (AOAA $10 \mu \mathrm{M}, \gamma$-vinyl-GABA $100 \mu \mathrm{M}$ ), AOAA and $\gamma$-vinylGABA raised the GABA level in the slice, whereas methoxypyridoxine and 3-mercaptopropionic acid reduced it. At high concentrations of these agents $(1 \mathrm{mM})$, both AOAA and $\gamma$-vinyl-GABA were not effective in raising the GABA level. Methoxypyridoxine (1 mM) was ineffective in reducing the GABA level, although 3-mercaptopropionic acid reduced the GABA concentration by $43 \%$. The effect of these agents on the isolated pancreatic islets was essentially similar to that of the hippocampal slice. Haber et al. reported that nonneural GAD was activated by AOAA, whereas the neural GAD was inhibited by the agent. ${ }^{8)}$ However, our previous study on the properties of GAD in the human insulinoma ${ }^{9}$ did not support this result and showed that non-neural GAD has the same properties as neural GAD. In the present investigation, AOAA, $\gamma$-vinyl-GABA, methoxypyridoxine and 3-mercaptopropionic acid showed the similar effect on the GABA level both in the pancreatic islets and in the hippocampal slice. This may indicate that GAD and GABA-T in the pancreatic islets, a non-neural tissue, have the same properties as those in the hippocampal slice, a neural tissue.

Acknowlegdements. Great thanks go to the Centre de Recherche Merrell Internationale, Strasbourg, for the supply of $\gamma$-vinyl-GABA. The authors thank Mrs. Fumiko Kurosawa for her skillful technical assistance.

\section{References}

1) Okada, Y., Nitsch-Hassler, C., Kim, J. S., Bak, I. J., and Hassler, R.: Exp. Brain Res., 13, 514-518 (1971).

2) Okada, Y., Taniguchi, H., Shimada, Ch., and Kurosawa, F.: Proc. Japan Acad., 51, 760-762 (1975). 
3) Roberts, E., and Simonsen, D. G.: Biochem. Pharmacol., 12, 113-134 (1963).

4) Jung, M. J., Lippert, B., Metcalf, B. W., Böhlen, P., and Schechter, P. J.: J. Neurochem., 29, 797-802 (1977).

5) Purpura, D. P., and Gonzales-Monteagudo, O.: J. Neuropath. exp. Neurol., 19, 421-432 (1960).

6) Nitsch, C., and Okada, Y.: Brain Res., 105, 173-178 (1976).

7) Karlsson, H., Fonnum, F., Malth-Sørensen, D., and Storm-Mathisen, J.: Biochem. Pharmacol., 23, 3053-3061 (1974).

8) Haber, B., Kuriyama, K., and Roberts, E.: Biochem. Pharmacol., 19, 11191136 (1970).

9) Okada, Y.: Proc. Japan Acad., 55B, 514-518 (1980).

10) Lacy, P. E., and Kostianovsky, M.: Diabetes, 16, 35-39 (1967).

11) Lowry, O. H., Rosebrough, N. J., Farr, A. L., and Randle, R. J.: J. Biol. Chem., 193, 265-275 (1951).

12) Okada, Y., Taniguchi, H., and Shimada, Ch.: Science, 194, 620-622 (1976).

13) Kuriyama, K., Roberts, E., and Rubinstein, M. K.: Biochem. Pharmacol., 15, 221-236 (1966). 